\title{
Los niveles metaficcionales en Pagliacci
}

\section{Metafictional Levels in Pagliacci}

\author{
Adrián Díaz Hilton \\ Universidad Nacional Autónoma de México \\ adriandiazhilton@gmail.com \\ orcid.org/oooo-0oo2-4874-6974
}

Resumen: Los niveles metaficcionales en la ópera Pagliacci (Payasos) de Rugiero Leoncavallo constituyen un concepto de realidad dispuesto en funciones dramáticas e interpretativas. Por medio de un análisis hermenéutico y semiótico, este ensayo pretende explicar cómo la metaficción crea un vínculo de significado entre lo real y lo ficticio. A partir del verismo integrado en la obra se desarrolla una interpretación hermenéutica que depende de los puntos de vista del espectador, los actores y el director. Para develar el fenómeno de interpretación y significación, el libretista propuso jugar con los planos de realidad y ficción, creando así un enigma enmarcado en una metaobra. Se concluye que la metaficción va más allá de solo una estructura dentro de otra que se explica a sí misma, sale de los márgenes de la realidad, la ficción y la imaginación del espectador, y construye la significación de la obra.

Palabras clave: Pagliacci, metaficción, metateatro, verismo, significación, interpretación

Abstract: $\quad$ Metafictional levels in Rugiero Leoncavallo's Pagliacci (Clowns) establish the concept of reality set in dramatic and interpretative functions. This essay aims to explain, throughout a hermeneutic and a semiotic analysis, how metafiction creates a meaningful link between reality and fiction. Here, a hermeneutic theory that relies on the spectator's, actor's and the director's point of view is developed from the concept of verism. The author of the libretto plays around within the planes of reality and fiction to create an enigma that explains the meaning and interpretation phenomenon using a metaplay as a frame liaised by a mise en abyme. It is concluded that metafiction reaches beyond a single structure within another that explains itself, it leaves the margins of reality, fiction and the spectator's imagination, and builds the oeuvre's signification.

Keywords: Pagliacci, metafiction, metaplay, verism, meaning, interpretation

Recibido: $\quad 18$ de octubre de 2019

Aceptado: $\quad 24$ de enero de 2020 


\section{La obra y su entorno}

La ópera Pagliacci ${ }^{1}$ de Rugiero Leoncavallo (1857-1959), estrenada en 1892, es un ejemplo muy claro del vínculo dramático que puede lograr el teatro entre el autor y el espectador atravesando la significación por el libreto, los directores, diseñadores, bailarines y cantantes-actores; el evento operístico es una acumulación de distintas ramas del arte; gracias a ello encontramos una mayor claridad de significaciones e interpretaciones que en un evento artístico de índole mayormente subjetiva (narrativa, poética, música). La significación de tal género dramático-musical es codependiente de la reestructuración cognitiva - a la manera de interpretación o al 'cómo se piensa'- de cada miembro del público para pertenecer al universo diegético in acto de la representación, es decir, la interpretación de la obra teatral a través de un director y actores invita al espectador a racionalizar sobre qué tan real es la realidad y qué tan ficticia es la ficción, y la metaficción fue la herramienta retórica que el libretista ${ }^{2}$ de esta obra usó como puente entre ambos significados. Para descifrar el fenómeno significación $\leftrightarrow$ interpretación es necesario revelar este vínculo, y la representación "realista", "verdadera" (vera), construida en la ópera de finales del siglo XIX y principios del xx, le da pie al espectador a brincar a este confuso viaje de dudas de si nuestro "actuar" en el mundo es verdadero o es una fantasía.

El verismo fue una corriente literaria influenciada por el realismo francés de mediados del XIX, donde Honoré de Balzac (1799-1850) proponía en sus novelas una ficción que representaba situaciones extraordinarias dentro de un estrato social no extraordinario - el vulgo- . Al llegar el final de siglo los italianos buscaban formas expresivas apegadas a la experiencia políticosocial fermentada durante un siglo de guerras de unificación e independencia; su revolución musical de inicios del barroco - la ópera - rindió frutos nuevamente en el siglo XIX con Nabuco (1841), de Giuseppe Verdi (1813-1901), de la cual brotó un símbolo de "resurgimiento" y de unificación con el movimiento coral "Va pensiero", escena en la que los esclavos se levantan contra sus capataces; en las calles y paredes rayaban letreros de "Viva V.E.R.D.I.!" (acrónimo de "Viva Vitorio Emmanuelle, Re Di Italia!") apoyando el estable-

1 La traducción del título de la obra es Payasos, el cual será usado como un juego polisémico relevante a la metaficción.

2 Para este análisis es imprescindible separar al libretista del compositor, aunque en ambos casos es el mismo autor. La significación del libreto es enriquecida por la de la composición, pero significan por medio de distintas funciones. 
cimiento de un nuevo reinado (Balthazar 2004: 37-38). Después de esta tormenta del Risorgimento vino la calma del conservadurismo, y en este crisol de identidad, movimiento social y música se forjaron los veristas, escritores de finales de siglo tras el estandarte teórico de Luigi Capuana (1839-1915) y el narrativo de Giovanni Carmelo Verga (1840-1922). Este contexto social mostró que Italia necesitaba un nuevo camino expresivo, con el cual quedó manifiesto que por medio de los arranques de pasión, celos y lujuria se puede abrir brecha en el público de arte, y se puede construir el pathos. La nueva literatura, "from the works of the Sicilian veristi, an entirely new literary landscape emerged: one devastated by nature and dominated by the blind passions and voracious instincts of characters for whom economic survival is the one and only motive force of existence",3 (Brand y Pertile 2008: 463) se enfocó en presentar campesinos y pueblerinos plenos en impulso instintivo hacia la explosión emocional por medio del asesinato, el suicidio y la venganza.

Los libretos veristas de ópera más sobresalientes son Cavalleria rusticana de Guido Menasci, compuesta por Pietro Mascagni; Carmen de Ludovic Halévi, compuesta por Georges Bizet y La boheme de Giuseppe Giacosa, compuesta por Giacomo Puccini. Todos muestran una 'poetica del vero' ('poética de lo verdadero', propuesta por el teórico Capuana para definir esta corriente), una representación de la realidad significada y escenificada en el vulgo; entre campesinos la primera, la segunda entre gitanos y la última, propiciando la ironía, entre artistas citadinos pobres. El elemento de un estrato social bajo agrega a la significación de 'verdadero', relacionándolo con la vida 'cotidiana', donde es poco probable un evento extraordinario. El mismo Capuana decía que la obra de arte es un ser viviente y cobra vida a través del actor verosímil:

Quando l'artista riesce a darmi il personaggio vivente davvero, non so chiedergli altro e lo ringrazio. Mi pare ch'egli m'abbia dato tutto quello che dovea. Pel solo fatto di esser vivente, quel personaggio è bello, è morale; e, se opèra bene e se predica meglio, non nuoce: tomo a ringra-ziar l'artista del di più. E al pari del personaggio amo viva l' azione. L' azione allo stesso modo, pel solo fatto di esser vivente è bella, è morale; non bisogna pretendere l'assurdo (Capuana 1872: XI).4

3 "devastada por la naturaleza y dominada por las pasiones ciegas e instintos voraces de personajes para quienes la supervivencia económica es la única fuerza motivante de la existencia" (traducción y cursivas mías).

4 [Cuando el artista logra darme realmente el personaje viviente, no sé qué más darle y le agradezco. Me parece que él me había dado todo lo que debía darme. Por el solo hecho de ser viviente, aquel personaje es bello, y moral; si ejecuta bien y predica 
Idea que resurge más tarde en el prólogo de Pagliacci en forma inversa: el personaje expone al público su 'humanidad' y su 'verdad' y le hace saber que es "de carne y hueso".

Pagliacci trata de una tropa de actores: Canio, el jefe; Nedda, su esposa; Tonio y Beppe, actores; quienes llegan a un pueblo para llevar a cabo una representación de Commedia dell'Arte. Este metateatro o metaobra (obra dentro de la obra) toma el modelo de personajes tipo: Pagliaccio (Canio), el patrón detrás de la sirvienta; Colombina (Nedda), la sirviente en espera de un amante; Taddeo (Tonio), sirviente y pretendiente de Nedda, y Arlecchino (Beppe), su amante. Esta obra interna es cómica y los actores vestidos de payasos interactúan persiguiéndose entre ellos sin lograr su objetivo: Colombina persigue a Arlecchino, Taddeo a Colombina, y Pagliaccio a Tadeo y a Arlecchino, de manera similar a la futura comedia de enredos (Fisher 2015: 2-3). El coro, representando al pueblo y, a veces, a otros payasos no caracterizados de la tropa, funge dentro de la obra como el público que va a presenciar esta comedia trágica. Cabe aclarar, esta 'obra dentro de la obra' no es la estructura esencial para provocar el enigma metaficcional en el espectador, ni es la que establece el vínculo analizado en este ensayo, sino su texto.

\section{Planos de interpretación}

Para lograr una definición de las funciones metaficcionales es necesario adentrarnos en ellas por medio de la hermenéutica, la semiótica y la pragmática; la metaficción, como veremos, no es una mera figura de uso retórico-estructural con función apelativa, sino que es en esencia una figura significativa dispuesta con el objetivo de retar intelectual y emocionalmente al intérprete primario. En su Semiótica del teatro, Fernando de Toro propone

mejor, no hace daño, vuelvo a agradecer al artista una vez más. Y a la par del personaje amo la acción viva. La acción, de la misma manera, por el solo hecho de ser viviente y bella, y moral, no debe pretender al absurdo" (traducción mía). Davvero aquí se puede traducir con las acepciones 'de verdad', 'de veras', 'realmente', por lo que juega con la polisemia y la pragmática de la locución. Asimismo, vale la pena recalcar la relación lexicosemántica que hay entre 'vero' y 'veritas' en el latín como lengua de origen del italiano y del español; en el primero se mantuvo esa relación, pero el español sufrió un cambio lingüístico resultante en que ahora traducimos vero con ambas acepciones, 'real' y 'verdadero' — considerados como términos independientes en filosofía, pero sinónimos en literatura-, razón por la cual se puede confundir entre 'realismo' francés y 'verismo' italiano. 
analizar el libreto como un discurso y como un texto para lograr una relación pragmático-lingüística en la interpretación de la obra de teatro (Toro 1987: 19-86), esto es, para utilizar los términos de la pragmática, como plantilla o tablilla de interpretación, en la que se relacionan las estructuras dramáticas con la terminología pragmática; la obra de teatro por sí misma significa para quien desee interpretar y no para sí misma, esto abre un punto de perspectiva externo para indicar quién significa y quién interpreta.

El intérprete primario de la obra de teatro es el espectador y el significador primario es la obra de teatro en integridad. Los actores son normativamente llamados 'intérpretes', ya que ellos leen la obra e interpretan el significado propuesto por el guionista y lo que llega al espectador es la 'interpretación' del actor; sin embargo, al actuar, la acción dramatúrgica ${ }^{5}$ puesta en escena para la interpretación de otros es en realidad una significación; en otras palabras, el actor como tal es un intérprete de la obra para sí mismo, mas, un significador para el intérprete primario. Además, dentro del eje dramático existe un sistema dialéctico en el cual se toman turnos - tal como es supuesto en teorías de análisis del discurso-, dentro de los cuales un personaje significa y otro interpreta. De esta manera podemos enmarcar diferentes planos de significación en el evento "obra teatral":

\begin{tabular}{|c|c|c|}
\hline $\begin{array}{l}\text { Intérprete } \\
\text { Primario }\end{array}$ & $\begin{array}{l}\text { Significador } \\
\text { Primario }\end{array}$ & $\begin{array}{l}\text { Significadores e intérpretes en un } \\
\text { sistema dialógico secundario (obra) }\end{array}$ \\
(Público) & & (Escenario) \\
\hline
\end{tabular}

5 Habermas establece que "El concepto de acción dramatúrgica no hace primariamente referencia ni a un actor solitario ni al miembro de un grupo social, sino a participantes en una interacción que constituyen los unos para los otros un público ante el cual se ponen a sí mismos en escena. El actor suscita en su público una determinada imagen, una determinada impresión de sí mismo, al desvelar con más o menos intención su propia esfera de sus propios sentimientos, pensamientos, actitudes, deseos, etc., a la que solo él tiene un acceso privilegiado. En la acción dramatúrgica, los implicados aprovechan esta circunstancia y gobiernan su interacción regulando el recíproco acceso a la propia subjetividad, la cual es siempre exclusiva de cada uno. El concepto aquí central, el de autoescenificación, significa, por tanto, no un comportamiento expresivo espontáneo, sino una estilización de la expresión de las propias vivencias, hecha con vistas a los espectadores" (Habermas 2014: 118). Con esto apela tanto a la función discursiva de expresar sentimientos y emociones como a 'actuar' para otros. 
A pesar de los diferentes ejes de significación, dentro del sistema hay un eje con la función de soporte de todos: la esencia del teatro se encuentra en la presentación de un guion —significador original-, interpretado y resignificado por un director - significador secundario- y los actores en escena -significador primario-, el cual contiene dentro de sí un eje dialógico secundario - significadores e intérpretes secundarios-, todo esto representado para un grupo de espectadores -intérprete primario- . Los planos de la significación son dispuestos en los ejes mencionados. El plano global se funda en el eje de significación lineal desde la obra hacia el público; rara vez interactúa el actor con el espectador y lo idealiza como dialógico; algunos ejemplos de esta interacción son los diálogos aparte, usados comúnmente en comedias para expresar directamente un diálogo al público. El plano dramático es un sistema dialógico dado en el guion -o la improvisación, si ese es el caso- entre los personajes. El punto de vista del intérprete analítico va a enmarcar el cómo será su análisis, interpretación y crítica dependiendo del plano en el que se coloque: para la semiótica del teatro, es necesario el plano global, ya que depende de cómo se percibe la obra como un todo para su significación; para la dramaturgia, solamente el plano dramático; para la pragmática, ambos, interpretados por medio de la significación contextual y situacional. Pero, el intérprete promedio, dentro de una interpretación inicial y simple, presta su atención y, por medio de su imaginación, se coloca en alguno de estos planos tratando de ser partícipe de ellos.

En el ramo de la hermenéutica, Gadamer (2003:319-347) y, en la semiótica, Lotman (1996: 52-56) incurrieron en la interpretación de un texto por medio de su relación con la percepción del mundo y con la verdad, o como una forma de representación del mundo real. El teatro, como significador de un 'evento situado en contexto y situación', ofrece una versión de la realidad supuesta entre personajes representados realmente por actores, la cual ha sido dispuesta en un texto escrito, al mismo tiempo que la música significa un texto musical y lo ejecuta dentro de la misma obra. Esta complejidad interpretativa se agrega a la dificultad de interpretación del director; sin embargo, para el espectador es más fácil: este llega preparado para entrar imaginariamente en el plano dramático y pertenecer a su realidad por medio de su interpretación sintética o imaginaria. Andrei Vishedskyi y Rita Dunn definen la imaginación como síntesis mental, una forma adquirida de sus estudios de neurología, en los cuales concluyeron que la imaginación es una síntesis (mezcla, unión) de distintos elementos almacenados en la memoria visual, al parecer 
irrelevantes, en la que influye la corteza prefrontal —relacionada a la 'acción' o 'voluntad'- (Vishedskyi y Dunn 2015). Esto es, el ser humano es capaz de emular una semiósfera temporal por medio de su síntesis mental en la que 'lo real' y el mismo espectador no pertenecen al plano global del teatro, sino al dramático de la obra; esto conlleva a que la interpretación más sencilla y, por tanto, la que puede usar un espectador sin ser un crítico teatral o un dramatólogo, es la sintética; además, a que el espectador "brinca" imaginativamente entre planos y trata de pertenecer significativamente al dramatúrgico.

Por otro lado, para el estudioso de las artes dramáticas es posible una interpretación dramática desde su semiósfera de conceptos dramatúrgicos, es decir, es una interpretación analítica. Estos conceptos enlazados en un paradigma, usados como una plantilla o tablilla de interpretación, como regla de medir, formada por términos y sus conceptos de dramaturgia, le permiten interpretar con precisión en una comparación de términos y objetos más allá de la capacidad del espectador promedio y significar en forma de crítica. A pesar de esto, la mayoría de ellos no se ha dado a la tarea de estudiar la plantilla de interpretación de un músico: materias como armonía, contrapunto, fraseo, estructura, entre otras, necesarias para la interpretación musical - también analítica-; en otras palabras, usamos estos paradigmas para subtipos de interpretaciones analíticas. Esto no impide que tanto el dramaturgo no músico como el espectador no músico ejerzan un tipo de interpretación general y cercana a la familia de la sintética; en el caso de la música es más fácil “dejarse llevar" o experimentar lo estético por medio de la interpretación patológica o la estética. El guion, tal como la música, es enmarcado en estructuras de distintos tipos, siendo la curva dramática la más común e inteligible, la cual pretende encender retóricamente el pathos de la audiencia por medio de la construcción de puntos de tensión dramática desde un origen neutral y la disposición estratégica, para lograr un crecimiento hacia el clímax — siendo aquí el crecimiento el punto más importante- Por ejemplo, el guion de $\mathrm{Pa}$ gliacci; su introducción presenta un punto de tensión menor que solo capta la atención del público y contextualiza la obra (función de exordio en retórica); sin embargo, mientras avanza la obra y se devela 'la verdad' a Canio y expresa su descontento en la afamada aria "Vesti la giubba" (punto de tensión), se construye este padecimiento, lo agónico, que concluye en un clímax pasional para el intérprete primario, quien ha imaginado pertenecer a esa construcción sintéticamente gracias a la contextualización de lo 'real' del escenario. La música funciona igual: por medio de tensión y distensión melódico-ar- 
mónica construye pequeños clímax (puntos de tensión) en cada movimiento de la ópera (aria, coro, recitativo, etc.); estos, aunque están apegados al libreto, también tienen una cierta independencia y pueden controlar el punto de tensión dramática enmarcándola en lo plenamente estructural -esencia de lo musical一. De esta manera, tanto en la música como en el drama, sin necesidad de conocimiento en las materias, puede haber una interpretación patológica dentro de un sistema complejo que despliega lo dramático y lo musical a través del tiempo. Por medio de esta, el intérprete primario, dejándose llevar por sus bajos instintos, crece en pasión junto a los actores para explotar en ira o compasión hacia Canio, por su desventura; hacia Nedda, por su desgracia; hacia Silvio, por su muerte, o en cinismo hacia Tonio, por propiciar todo el evento. $\mathrm{O}$, en su defecto, en emociones indefinidas y cruzadas, pero grandes, que provoca la orquesta al explotar en un 'fff tutta la forza' ${ }^{6}$ al final de la ópera, donde el tema es plenamente musical. Este tipo de interpretación es construida principalmente por la ejecución musical y secundariamente por el guion; en otras palabas, la música es el marco estético, retórico y, esencialmente, temporal de la ópera. Esto mismo también precisa cómo el intérprete primario enmarca estructuralmente, gracias a la música, cada figura retórica y las categoriza por medio de sus valores cuantitativos dependiendo de su posición en la curva dramático-musical; el guion, más la composición, llevan de la mano emocional y estéticamente al espectador.

\section{Niveles ficcionales y metaficcionales}

Los tipos de interpretación en ambos planos, en especial los que sitúan al espectador en una realidad dentro de sí mismo, son los ejes por los cuales el mismo intérprete primario dará cuenta de la presencia de metaficción y, si es más analítico, de todos sus niveles. El primer nivel, necesario para la oposición de los subsecuentes es la 'realidad', el lebenswelt (mundo de la vida) según Husserl (1991: 145-146), Blumenberg (2013: 11-12) y Habermas (2014: 101-107, 170), el mundo de los realia. Sin la conciencia del espectador de entrar a un edificio denominado 'teatro' para presenciar una realidad alterna no habría el segundo nivel, la ficción; en las artes escénicas ambos niveles son esenciales y codependientes; el público es parte de la obra; su interpretación completa el círculo comunicativo; sin este, no hay evento artístico como tal.

6 'Fuertísimo, toda la fuerza' (Leoncavallo 1952: n. e. 150). 
Como un nivel de realidad, la obra presenta una 'realidad irreal dentro de lo real'; sin embargo, aunque esto puede significar como una paradoja, presentarla como tal no es la intención comunicativa del artista; tampoco es una representación de la realidad enfocada a lo verdadero o lo verosímil. La intención se encuentra en la interpretación sintética y en la interpretación patológica; la experiencia estética no llega a través de una interpretación analítica, sino de experimentar los diversos valores estéticos; es decir, no de percibirla, sino de significarla y padecerla. De allí que el espectador esté preparado para interpretar voluntariamente a su manera y capacidad, dispuesto a entrar imaginariamente en la obra.

La ficción es perfectamente una invitación a la síntesis mental en la narrativa; ofrece una descripción para ser interpretada a placer por el lector. Mas, el teatro funciona en otra significación de ficción, en la cual el espectador entiende los sucesos como 'actuados', pero la situación le es presentada en tiempo real, para la cual es un testigo; su imaginación solo puede colocarlo dentro de la obra, pero él no imagina el escenario o los personajes, como en la narrativa; estos son el elemento de realidad dados por la tropa de actores, a pesar de ser una situación ficticia montada en el libreto. Desde aquí parte la metaficción hacia niveles más profundos, pero antes de brincar a otros niveles habrá que definir su función.

El intérprete primario presencia la significación primaria de manera voluntaria y la toma como real; así es como se vincula con la ficción, no por creencia, sino por pura significación. Este primer eslabón es otorgado solo por el espectador; el artista humano no ha encontrado todavía la manera de obligar a su audiencia a introducirse en la obra por la fuerza; por lo tanto, ninguna obra garantiza la misma experiencia para todos, pero el espectador, quien premeditadamente asiste para interpretar sintética y patológicamente, experimenta la significación intencionada por el autor subjetivamente, la padece a su manera.

La metaficción: "is a term given to fictional writing which self-consciously and systematically draws attention to its status as an artefact in order to pose questions about the relationship between fiction and reality" (Waugh 2001: 2).7 En el caso del teatro, es un guion que remite a sí mismo para agregar

7 "es un término dado a un escrito ficcional que autoconsciente y sistemáticamente llama la atención a su estado como un artefacto para cuestionar acerca de la relación entre la ficción y la realidad" (traducción mía). 
profundidad a la cadena de significación entre la obra y el espectador. Usada como figura retórica, es solamente un llamado de atención en un punto específico dentro de la obra, pero, usada como marco del mundo dramático en el que viven los personajes, es un vínculo con la función significativa para ayudar al espectador a pertenecer a este mundo o, viceversa, a que el mundo diegético pertenezca al real y a lograr su cometido patológico a la par de los personajes. Nuevamente, su intención no es generar una idea de paradoja, sino empujar al público al abismo de ser parte del mundo ficcional en el cual habrá un evento extraordinario.

El primer anillo del espacio ficcional de Pagliacci es la tropa de actores que llega al pueblo, este es el primer nivel ficcional, o, por aclarar, la obra presenciada por el espectador. El siguiente nivel inicia con la escena de Canio anunciando que al ocaso la tropa presentará una obra donde Pagliaccio le tenderá una trampa al amante de Colombina (Leoncavallo 1906: 39). Durante el primer acto se desarrolla el drama del primer nivel: Nedda comete adulterio con Silvio, un habitante del pueblo; Tonio quiere a Nedda, pero ella lo rechaza y este la encuentra in flagrante engañándolo; él da aviso a Canio y planta los celos, a partir de los cuales se desarrollará el clímax. El gatuperio entre la tropa y el pueblo, donde se lleva a cabo el evento extraordinario en torno a los celos y el asesinato, es la característica principal del verismo.

El primer nivel metaficcional ${ }^{8}$ se presenta en el segundo acto, donde se lleva a cabo el metateatro, el cual ha sido preparado patológicamente por el drama del primer acto. La tropa se presenta como sus metapersonajes en este nivel y desarrollan el drama interno: Colombina quiere a Arlecchino de amante, quien le ofrecerá serenata; Taddeo la ayudará a conseguirlo, mientras Pagliaccio tratará de evitarlo. Cabe recordar que esta puesta en escena es una representación típica de Commedia dell'Arte, por lo que hay un supuesto de improvisación en los personajes tipo (Rudlin 1994: 106-133). El metateatro, como obra dentro de la obra, no establece por sí mismo el vínculo entre lo real y lo ficticio en el espectador; su función elemental es plantear en contexto y situación el siguiente nivel significativo, es decir, el primer nivel metaficcional. Dentro del terreno de juego dispuesto se llevará a cabo la acción dramatúrgica con la única intención de significar y establecer el vínculo, por

8 En este ensayo no se considera la metaficción como un segundo nivel ficcional, ya que, en términos del relato ficcional, este sería más bien un relato dentro del relato (“x le dijo a y que..., "me contaron que...", etc.), mientras que en los niveles metaficcionales se busca la autoexplicación. 
esto mismo el marco metaficcional es necesario: se llevará al espectador a este nivel junto al actor, quien no está contando a otro lo que vivió, más bien, con mayor énfasis en lo real, está llevando al escenario entero y a los actores a este nivel. Ahora tenemos al público real y al ficcional del primer nivel como testigos del evento y como intérpretes primarios. Al disponer este nivel se revela una serie de paralelismos entre los distintos planos de significación:

\begin{tabular}{l|l|ll} 
Interpretación & \multicolumn{2}{|c}{ Plano global } & \multicolumn{2}{c}{ Plano dramático } \\
\hline Nivel ficcional & realidad & ficción & metaficción \\
Espacio & teatro & escenario & escenario interno \\
Público & público como testigo & público ficticio (coro) & actores en escena \\
Actores & cantante de ópera & actor de la tropa & personaje \\
Función & $\begin{array}{l}\text { espectador signi- } \\
\text { dramática }\end{array}$ & Canio, & Pagliaccio, \\
& $\begin{array}{l}\text { fuera de la ficción } \\
\text { como testigo }\end{array}$ & Silvio & Colombina, \\
& & & Alrecchino
\end{tabular}

De este paralelismo surge el concepto de metaficción. El espectador tomará la significación brincando de plano en plano, interpretando de diversas maneras - de preferencia para el autor, interpretación patológica y sintética- el mundo tan real y ficticio que lo rodea, en el cual se ha inmiscuido voluntariamente. Estos cambios de plano, de nivel ficcional y metaficcional son parte de las metaestructuras necesarias para la 'definición del sí, por sí mismo' a las cuales remite Waugh; la autoconciencia solo puede suceder cuando el elemento traspasado a los otros niveles lleva consigo una carga significativa de contexto y situación desplegada entre lo real y lo ficticio, pasando de una a otra significación, hasta que vuelve a la original, la 'real'. El enigma propiciado por la obra debe ser ordenado por el intérprete cuando trata de descubrir el mensaje oculto; incluso la moraleja como metáfora teatral. Además, porque el proceso de transferencia de elementos entre niveles ofrece significación al intérprete, se obtendrá una satisfacción del logos por su entendimiento.

Aquí entra en juego el concepto de mise en abyme (puesta en abismo). El paralelismo entre el nivel ficcional y el metaficcional deja en tela de duda qué tan real puede ser el plano global y cuáles son los finales posibles para ambos niveles. De esta manera, Canio, actuando como Pagliaccio, obtiene su anagnórisis principal de esta metaficción imitando el plano global dentro 
del primer nivel ficcional: "Nome di Dio! quelle stesse parole!"9 (Leoncavallo 1906: 184); cae en cuenta de su desdicha: sucede lo mismo en la obra y en su 'vida real'. Así es como el espectador también revela en sí mismo la metáfora teatral, propuesta en el Renacimiento y analizada recientemente por Curtius (2017: 203-211): ¿Es el teatro una actuación fantasiosa o es real? ¿Es la vida real una actuación fantasiosa?

Un análisis detallado del prólogo en contraste con el aria: "Vesti la giubba", y el final de la ópera, deja más en claro cómo el discurso entretejido en los diálogos es el portador de la metaficción. El primer punto relacional es el texto del aria contenida en el prólogo: se presenta Taddeo, el personaje de la metaobra — no Tonio, el personaje de la obra — frente al intérprete primario, quien dice: "L'autore ha cercato invece pingervi uno squarcio di vita. Egli ha per massima sol che l'artista è un uom e che per gli uomini scrivere ei deve. Ed al vero ispiravasi!" (Leoncavallo 1906: 10). ${ }^{10}$ Contextualiza así la obra dentro del verismo, pero, al mismo tiempo, habla del actor como un humano perteneciente al mundo de lo real; es el primer vínculo hacia el público - ¿el real o el ficticio?-, se dirige al intérprete primario como si fuera uno secundario o ficcional (secuela de la teoría de Capuana), lo cual será revelado en el segundo acto, cuando surge este prologuista como personaje de la metaobra. "Un nido di memorie in fondo a l'anima cantava un giorno, ed ei con vere lacrime scrisse, e i singhiozzi il tempo gli battevano!" (Leoncavallo 1906: 11). ${ }^{11}$ Con esto trata de establecer el vínculo patológico con el 'personaje de lo verdadero' desde el inicio, y claramente el foco del pathos será la tragedia - la cual, agregando a la ironía, será propiciada por la batuta de Tonio-. "E voi, piuttosto che le nostre povere gabbane d'istrioni, le nostr'anime considerate, poiché siam uomini di carne e d'ossa, e che di quest'orfano mondo al pari di voi spiriamo l'aere!" (Leoncavallo 1905: 13-14). ${ }^{12}$ Así culmina el vínculo inicial e insiste en la persona del actor, en su alma y cuerpo humano, en su 'reali-

9 [¡Dios mío! ¡Las mismas palabras!] (traducción mía).

10 [El autor ha buscado esta vez retratar un tajo de vida. Tiene por máxima única que el artista es un hombre y que para el hombre debe escribir. ¡Y en la realidad se ha inspirado!] (traducción y cursivas mías).

11 [Un nido de memorias en el fondo del alma cantaban un día, y con verdaderas lágrimas escribió, iy sus sollozos llevaban la batuta del tiempo!] (traducción y cursivas mías).

12 [Y vosotros, más que nuestros pobres andrajos de histriones, nuestra alma considerad, porque somos hombres de carne y de hueso, iy que de este huérfano mundo a la par de vosotros respiramos el aire!" (traducción y cursivas mías) Aquí huérfano refiere a 'solitario'. 
dad'. Al presentarse el personaje de la metaobra ante el espectador crea una especie de trompe-l'oeil (trampantojo) con el que significa al público como perteneciente al público ficcional, o, mejor dicho, lo invita a significarse en el plano ficcional. Esta figura retórica de la pintura y la arquitectura forma un "gancho realista" entre la obra y el espectador, de la misma manera en la que Taddeo abre la significación primaria ante el público y después aparece como personaje de la metaobra, significando así que ambos públicos, real y ficticio, son uno mismo; o sea, se dirige al intérprete primario en segunda persona desde el nivel metaficcional, no desde el primer nivel ficcional, para atraerlo o invitarlo a brincar al primer nivel ficcional.

El aria "Vesti la giubba" actúa en oposición al prólogo para provocar un choque de significaciones: el actor de la vida dramática en contra del actor de la vida real; así es como se encuentran el plano global y el plano dramático para tener como resultado otro tanto de posibles significaciones. "Recitar! Mentre presso dal delirio non so più quel che dico e quel che faccio! Eppur è d'uopo, sforzati! Bah! Sei tu forse un uom? Tu se' Pagliaccio!' (Leoncavallo 1906: 129-130).13 Actúa desesperado y confuso mientras, nuevamente, no distingue entre el actor y el hombre. En este diálogo vale la pena abrir un paréntesis sobre el ser y la identidad de Canio y Pagliaccio; "Tú eres Payaso", la polisemia que hay entre el nombre del personaje y las distintas acepciones de 'payaso' permiten una significación metafórica entre el personaje que representa al hombre verdadero y el ficticio, entre lo identificable como mundo de la vida en contra de 'la obra en mi presencia' por el espectador - todo resulta en que vivir no es más que una mentira actuada-. "Vesti la giubba e la faccia infarina. La gente paga e rider vuole qua. E se Arlecchin t'invola Colombina, ridi, Pagliaccio, e ognun applaudirà!" (Leoncavallo 1906: 130-131). ${ }^{14}$ Aquí el 'payaso' dentro del 'hombre' explota y se confunde a sí mismo, crea un vínculo entre el nivel metaficcional (actor-Payaso) y el ficcional (actor-'payaso'). Mientras el prólogo preparó la significación para pertenecer, como público, al mundo dramático, "Vesti la giubba", ahora, ya atrapada la significación del

13 [¡Recitar, mientras preso del delirio no sé más lo que digo y lo que hago! ¡Además, y apropiadamente, haz el esfuerzo! ¡Ah! ¿Eres acaso un hombre? ¡Tú eres Payaso!] (traducción y cursivas mías). Aquí juega con la polisemia de 'recitar' como 'actuar' y como 'cantar' dentro del recitativo en el que canta en ese instante, y al mismo tiempo hace referencia al recitativo en el cual reclamará a Nedda-Colombina su adulterio.

14 [Viste la túnica y tu cara enharina. La gente paga y reír es lo que quiere. Y si Arlequín te roba a Colombina, jríe, Payaso, y cada quien aplaudirá!] (traducción mía). 
intérprete primario por medio del prólogo, expresa su cometido real: el payaso-persona ha sido engañado, está en el punto de quiebre, sucumbirá a la ira.

En la disposición de las funciones dramáticas de los personajes sobre las tres partes de la obra se puede entrever a la metaficción como un hilo conductor de la significación entre 'lo real' y ‘lo ficto’:

\begin{tabular}{|c|c|c|c|}
\hline Acto & Plano & Tonio & Canio \\
\hline Prólogo & Plano global & $\begin{array}{l}\text {-Trampantojo: } \\
\text { origen y fin de la } \\
\text { metaficción }\end{array}$ & \\
\hline I & Nivel ficcional & -Plantar celos & $\begin{array}{l}\text {-Metáfora } \\
\text { teatro-vida }\end{array}$ \\
\hline II & $\begin{array}{l}\text { Nivel } \\
\text { metaficcional }\end{array}$ & $\begin{array}{l}\text {-Control de los } \\
\text { implicados }\end{array}$ & $\begin{array}{l}\text {-Puesta en } \\
\text { abismo } \\
\text {-Clímax }\end{array}$ \\
\hline
\end{tabular}

Más allá de ser el tema o el marco estructural, la metaficción en Pagliacci funciona como un vínculo, un eslabón directo, entre el intérprete primario y el plano dramático. Cumple con su función retórica y como herramienta semiótica para lograr que el espectador entienda cómo funciona la obra y su autoexplicación, pero la función principal es la hermenéutica: la de significar e interpretar para construir una red de signos y símbolos que agregan a la obra interés intelectual —más que prestigio y honra literaria—. El marco hermenéutico concluye en una misma interpretación que apela al logos. Aunque todavía queda pendiente la significación del cierre.

Solo hasta el final de la obra, cuando Tonio se devela como el personaje controlador de la situación, es él quien a la distancia atestigua el fruto de sus actos; observa cómo Nedda y Silvio son asesinados por Canio mientras dicta: "La commedia è finita!" (Leoncavallo 1906: 205). ${ }^{15}$ Así acaba la obra, en el clímax verista, en el asesinato. Esto conlleva a la interpretación patológica principalmente, a sucumbir en la ira junto al personaje primario; mientras,

15 [¡La comedia ha terminado!] (traducción mía). Comedia, con ambas acepciones de 'comedia' y 'obra teatral', refiere tanto a la comedia risible representada en el metateatro como a la ópera —-trágica—, la significación primaria. 
el marco metaficcional ha llevado al mismo espectador a una interpretación analítica, es decir, a sufrir una propia anagnórisis de cómo ha sido manipulado por el libretista a significarse como un miembro del mundo dramático. El espectador, desde el inicio, solo fue un personaje más.

\section{Bibliografía}

Balthazar, Scott (2004). The Cambridge Companion to Verdi. Cambridge, Cambridge University Press.

Blumenberg, Hans (2013). Teoría del mundo de la vida. México, Fondo de Cultura Económica.

Brand, Peter, y Lino Pertile (2008). The Cambridge History of Italian Literature. Cambridge, Cambridge University Press.

CAPuAna, Luigi (1872). Il teatro italiano contemporaneo. Palermo, Luigi Pedone Lauriel.

CURTIUs, Ernst (2017). Literatura europea y Edad Media latina, I. México, Fondo de Cultura Económica.

Fisher, Burton (2015). "Leoncavallo's Cavalleria Rusticana \& Mascagni's I Pagliacci”, Opera Classics Library Series. Miami, Opera Journeys Publishing.

GADAMER, Hans-Georg (2003). Verdad y método, tomos I y II. Salamanca, Ediciones Sígueme.

Habermas, Jürgen (2014). Teoría de la acción comunicativa, trad. Manuel Jiménez Redondo. Madrid, Editorial Trotta.

LeOncavallo, Ruggiero (1906). Pagliacci, vocal score. New York, G. Schirmer. Placa 18934. Traducción al inglés de Henry Grafton Chapman.

Leoncavallo, Ruggiero (1952). Pagliacci, fullscore. Primera edición: Milan, Sonzogno, 1892, placa E. 644. Segunda reimpresión: New York, Broude Brothers, 1952, placa B. B. 52.

Lotman, Iuri (1996). Semiósfera I, trad. Desiderio Navarro. Valencia, Frónesis Cátedra Universitat de Valencia.

RuduIn, John (1994). Commedia dell'Arte. An Actor's Handbook. London, Taylor \& Francis Group.

Toro, Fernando de (1987). Semiótica del teatro. Del texto a la puesta en escena. Buenos Aires, Editorial Galerna.

VISHEDSKYI, Andrei, y Rita DUNN (2015). "Mental Synthesis Involves the Synchronization of Independent Neuronal Ensembles”, Research Ideas and Outcomes. Artículo en línea disponible en: <https://riojournal.com/article/7642/>, consultado por última vez el 17 de abril de 2019.

Waugh, Patricia (2001). Metafiction. London, Taylor \& Francis e-Lybrary. 
Interpretatio, 5.2, septiembre 2020-febrero 2021: 207-222

\section{Adrián Díaz Hilton}

Licenciado en Canto por la Universidad Nacional Autónoma de México. Edición de partituras y textos musicales. Actualmente cursa la Licenciatura en Lengua y Literaturas Hispánicas en el Sistema Universidad Abierta de la UNAM. 